\title{
CONTAMINACIÓN SONORA EN EL PARADERO BENAVIDES, EN LA CIUDAD DE LIMA, Y EL IMPACTO EN POBLACIONES ALEDAÑAS
}

\author{
SOUND POLLUTION AT BENAVIDES STOPIN LIMA CITY \\ AND THE IMPACT ON POPULATIONS NEARBY
}

\author{
Jaime Sueldo Mesones' 1 , Lucero Romero Santos ${ }^{2}$, \\ David Bravo Zapata ${ }^{3}$, Clara Tufiño Villena ${ }^{4}$
}

RECEPCIÓN: 10 DE OCTUBRE DEL 2019

ACEPTACIÓN: 06 DE DICIEMBRE DEL 2019

\begin{abstract}
RESUMEN
La presente investigación comprende el estudio sobre de la contaminación sonora producida en el paradero del puente de la avenida Benavides, en la ciudad de Lima, lugar donde concurren muchos de los estudiantes de la Universidad Ricardo Palma. El estudio tuvo por finalidad analizar la realidad objetiva, con ayuda de un instrumento científico como es el sonómetro. De esa manera, se efectuaron mediciones diariamente, para capturar los sonidos causados por fuentes vehiculares de transporte público y privado. Además, se detectaron los altos niveles de contaminación a los que se llega y a los que están expuestos, tanto los usuarios del transporte público como son los alumnos de la universidad Ricardo Palma, que utilizan este paradero, así como, las personas que realizan actividades económicas como son, vendedores ambulantes y trabajadores asociados a la labor de transporte y otros transeúntes. Este trabajo investigativo tuvo dos fases, primero la realización de una encuesta, donde se aplicó un instrumento a una muestra de 151 individuos entre alumnos, personal administrativo de las Facultades de Ingeniería y Arquitectura, el cual evidenció que, el $96 \%$ de los encuestados manifestó ser consciente que la contaminación sonora les causa malestar a su salud, produciendo estrés, dolores de cabeza y pérdida de audición, y en una segunda fase, se realizaron mediciones con apoyo de un sonómetro en el área de trabajo, de las mediciones observadas se infiere que todas las que corresponden a las producidas por el claxon de las unidades de transporte público superaron
\end{abstract}

\begin{abstract}
This research includes the study of noise pollution produced at the whereabouts of the Benavides Avenue bridge, in the city of Lima, where many of the students from the Ricardo Palma University attend. The purpose of the study was to analyze objective reality, with the help of a scientific instrument such as the sound level meter. Thus, measurements were made daily to capture the sounds caused by vehicular sources of public and private transport. In addition, the high levels of contamination that are reached and to which they are exposed were detected, both the users of public transport and the students of the Ricardo Palma University, who use this location, as well as people who carry out economic activities. as they are, street vendors and workers associated with the transport work an other passers-by. This investigative work had two phases, first the completion of a survey, where an instrument was applied to a sample of 151 individuals among students, administrative staff of the Faculties of Engineering and Architecture, which evidenced that $96 \%$ of the respondents stated be aware that noise pollution causes discomfort to their health, causing stress, headaches and hearing loss, and in a second phase measurements were carried out with the help of a sound level meter in the work area, from the observed measurements it is inferred that all those corresponding to those produced by the horn of public transport units exceeded $100 \mathrm{~dB}$. and that on Friday, June 14, the highest record was recorded, $109 \mathrm{~dB}$. the same that affected 56 individuals who were at the measurement point. In this sense,
\end{abstract}

\footnotetext{
1 Escuela Profesional de Ingeniería Civil, Universidad Ricardo Palma. <jaime.sueldo@urp.edu.pe>

2 Escuela Profesional de Ingeniería Civil, Universidad Ricardo Palma. <lucero.romeros@urp.edu.pe>

3 Escuela Profesional de Ingeniería Civil, Universidad Ricardo Palma. <davicobz7@gmail.com>

4 Escuela Profesional de Ingeniería Civil, Universidad Ricardo Palma. <claratufinov@gmail.com>
} 
los $100 \mathrm{~dB}$. y que el día viernes 14 de junio, se tuvo el registro más alto, $109 \mathrm{~dB}$. el mismo que afectaba a 56 individuos que se encontraban en el punto de medición. En tal sentido, la realización de esta investigación se justifica porque, nos permite alertar sobre los altos niveles de contaminación sonora, a la que están expuestos todos aquellos que emplean el servicio de transporte, en el área objetivo y el impacto ambiental que se produce.

Palabras clave: Medición sonora, ruido, contaminación sonora, impacto ambiental. carrying out this research is justified because it allows us to alert about the high levels of noise pollution, to which all those who use the transport service are exposed, in the target area and the environmental impact that occurs.

Keyword: Sound measurement, noise, noise pollution, environmental impact

\section{INTRODUCCIÓN}

La presente investigación esta planteada de manera de responder preguntas de nuestro entorno común, de cómo diariamente estamos siendo contaminados sonoramente, cómo el ruido puede afectarnos en nuestra actividades cotidianas, nuestro desarrollo en la sociedad y como nuestra salud se puede ver perturbada, y para ello tenemos que descubrir la realidad donde se produce este fenómeno, para lo cual hemos tomado mediciones de contaminación sonora en un espacio altamente concurrido, muy próximo a la Universidad Ricardo Palma, donde interactúan muchos alumnos que utilizan el transporte público y que están expuestos a niveles de contaminación, la importancia de esta investigación radica en reconocer estos niveles de presión sonora, que tenemos que soportar, la misma que tendrá efectos auditivos temporales y efectos no auditivos, todas estas preguntas son respondidas en la presente investigación, en la fase exploratoria se recogen datos valiosos a través de una encuesta, en ellas los alumnos, parte de la muestra, coincidieron en reconocer que hay un daño producido por la contaminación que ellos perciben, y por otro lado las mediciones que se realizaron en nuestra área objetivo confirmaron cómo, los altos niveles de ruido, los que afectan a toda una zona de viviendas aledańas, pabellones internos de la universidad, como también a muchos transeúntes que utilizan la vía pública y especialmente a los que emplean el transporte público serán los más afectados. En encuestas de más de 30 estudios se conoce que la exposición al ruido, tanto de forma puntual como crónica, produce disminución en el rendimiento y la motivación, provocando la pérdida de defensas ante otros estresores [1, p. 51].

El ruido ambiental es uno de los principales elementos de contaminación en las ciudades modernas $[\ldots]$ los vehículos, con sus mecanismos, motores y el roce de neumáticos con el pavimento son los máximos responsables del ruido total en las grandes urbes [2, p.68], en la ciudad de Lima el transporte público está dado por omnibuses, de naturaleza informal cuyos choferes hacen uso recurrente a las bocinas, a manera de llamar a los pasajeros, emplean indebidamente este mecanismo que es uno de los factores más importantes que causa el ruido. La información sobre los aspectos relacionados a la contaminación global son cada día más recurrentes, estos son temas de discusión no solo en los ámbitos académicos, pero en la agenda de las comunidades todavía se desconoce cómo abordarlos, combatir la contaminación auditiva requiere una comprensión global sobre la generación del ruido, entender el grado de afectación que el uso del transporte conlleva y la manera como diversas políticas públicas, entre ellas el modelo de ciudad caminable, pueden dar pie a un cambio sustancial en la dinámica ciudad-ambiente [2, p. 70].

El ruido ambiental es uno de los principales elementos de contaminación en las ciudades modernas. De acuerdo con el Instituto del Ruido de Londres, los vehículos, con sus mecanismos, motores 
y el roce de los neumáticos con el pavimento, son los máximos responsables del ruido total en las grandes urbes [2, p.68], a éstos hay que sumarles que los transportistas de ómnibus de pasajeros hacen un inadecuado empleo de la bocina, la misma que les sirve para llamar a los pasajeros, o simplemente reclaman ocupar un espacio dentro de la vía, sin importar los graves daños que causan.

La contaminación acústica se define como la presencia en el ambiente de ruidos o vibraciones, cualquiera que sea el emisor acústico que los origine, que impliquen molestia, riesgo o dańo para las personas, para el desarrollo de sus actividades o para los bienes de cualquier naturaleza, o que causen efectos significativos sobre el medio ambiente [3, p. 13].

La contaminación sonora es la presencia, en el ambiente, de niveles de ruido que implique molestia, genere riesgos, perjudique o afecte la salud y el bienestar de los humanos, así como a los bienes de cualquier naturaleza, o que cause efectos significativos sobre el medio ambiente, tal como lo define la OEFA, [4] que es el Organismo de Evaluación y Fiscalización Ambiental.

Si el sonido es aquel que nos trasmite información, ideas, sensaciones, y nos permite comunicarnos con el entorno, también el ruido es aquel que interrumpe nuestra comunicación, es ajeno a nuestro interés, causa molestia, es nocivo, desagradable, y por tanto contamina nuestro ambiente [2, p. 71]. Esta sustancial diferencia está marcada por una valoración subjetiva, de quién define y percibe cuando el sonido es molesto, y ello da lugar a que el sonido se convierta en ruido.

La ciudad de Lima, es una metrópoli, que alberga una población por encima de los 10 millones de habitantes, siendo la de mayor población en el país, $[5$, p. 16] en el estudio sobre el futuro de la población peruana destaca que una característica central del sistema urbano peruano es la primacía de la capital Lima-Callao. Su población es diez veces mayor que la segunda ciudad del país, Arequipa (10 millones y casi un millón respectivamente). Esta primacía se ha mantenido desde hace por lo menos tres décadas como consecuencia del centralismo, con problemas de ordenamiento territorial, donde la ciudad ha crecido, sin una infraestructura de transporte proporcional a sus necesidades.

En la presente investigación, tomamos como objeto de estudio el paradero de Evitamiento del Puente Benavides, ubicado en el distrito de Surco. Éste se caracteriza por ser de intenso flujo vehicular y de bastante movimiento en los horarios de 7:00 a. m. a 9:00 a. m. y de 17:00 p. m. a 19:00 p. m., ya que se encuentra en el cruce de la Panamericana Sur y la Av. Alfredo Benavides. La investigación de campo se extendió desde el día lunes 10, hasta el día viernes 14 de junio de 2019.

El Organismo de Evaluación y Fiscalización Ambiental, entidad adscrita al Ministerio del Ambiente, impulsó una campańa de Medición del Ruido Ambiental en los 43 distritos de Lima Metropolitana y en seis distritos de la provincia de Callao, encontrando que el distrito de Santiago de Surco, donde se ubica nuestra unidad de análisis, tuvo niveles de contaminación sonora por encima de los estándares de calidad ambiental permitidos, con registros de $84.5 \mathrm{~dB}$, en una área de protección especial, evidenciando una notable vulneración a la norma, los otros distritos estuvieron entre 81.6 $\mathrm{dB}$ y $84.9 \mathrm{~dB}$.

Los niveles de ruido medidos en la estación ubicada en el centro de la ciudad de Lima (Jr. Chancay/ Av. Nicolás de Piérola), estuvieron en el rango de $90 \mathrm{~dB}$ a $122 \mathrm{~dB}$. Los criterios de evaluación se hicieron tomando en cuenta los regulados por la EPA (Environmental Protection Agency), [...]. Los niveles de ruido encontrados exceden los niveles máximos permitidos de $70 \mathrm{~dB}$ para zonas comerciales en horario diurno, lo que podría estar ocasionando encubrimiento;? y fatiga en la población [ 1, p.52].

El ruido del tráfico obra como un distractor con afecciones de la memoria y la atención, y afecta a la salud funcional del adulto mayor. El ruido no habitual libera adrenalina de la médula suprarrenal, y el habitual, noradrenalina del tono simpático. También, se elevan las catecolaminas si las actividades domésticas son perturbadas y el cortisol con la interferencia del sueńo [1, p. 51].

Las llamadas horas punta en la ciudad, que normalmente son definidas al inicio y al término de las jornadas de trabajo, hacen que la concurrencia de los usuarios del transporte público se acreciente, 
y el transporte informal no regulado por la autoridad, incorpora otro factor, los choferes carecen de calificaciones, y esta situación incrementa aún más el problema. Los estresores ambientales son las condiciones crónicas o globales del medio ambiente [1, p. 51]. La ciudad conjuga demasiadas actividades y producen estresores ambientales que contaminan al organismo, que afectan a la vista, las vías respiratorias y, especialmente, al oído, produciendo estados de ánimo negativos. Las personas se ven impedidas de interactuar con los demás. Este ruido ambiental incide sobremanera en la calidad de vida del ciudadano.

En un estudio realizado en la ciudad de Lima señaló, que los ciudadanos encuestados en número de 329 indican, como fuente principal generadora del ruido al tráfico vehicular. Lo califican de muy ruidoso el $63,5 \%$ y de ruidoso el 15,5\%. Como consecuencia de este análisis, los ciudadanos están conscientes que el Cercado de Lima alberga demasiado ruido [1, p. 53]

El comercio ambulatorio e informal se ubica en gran parte de los paraderos de transporte público de la ciudad y los comerciantes que se dedican a esta actividad soslayan esta problemática, ya que no están informados de sus consecuencias siendo esta actividad su fuente principal de ingresos.

Se han constatado numerosos efectos del ruido sobre la salud, que van desde la pérdida progresiva de audición, hasta alteraciones de la presión arterial, del ritmo cardíaco y de los niveles de segregación endocrina, insomnio, cefaleas crónicas, reducción de la capacidad sexual. Así mismo, el ruido aumenta en un $20 \%$ la posibilidad de sufrir infartos e incide sobre los estados de estrés e irritabilidad, que afectan negativamente la capacidad de concentración y aprendizaje, la productividad, la siniestralidad laboral y los accidentes de tráfico [6, p. 25]

Muchas clasificaciones se han dado para los efectos y daños que causa este tipo de contaminación, hay dos categorías básicas: las de tipo fisiológico auditivo y extrauditivo. Donde se señala que los efectos fisiológicos más directos y claros son de tipo auditivo [6, p. 25], y los mejor estudiados se relacionan con la sordera. La exposición continuada a niveles de ruido muy altos (superiores a $85 \mathrm{~dB}$ ) puede provocar la pérdida paulatina de audición, como ocurre con los trabajadores expuestos a estos niveles a lo largo de toda la jornada laboral y durante largos períodos de tiempo [...]. La pérdida es máxima para las bandas de frecuencia de 3.000 a $6.000 \mathrm{~Hz}$ y los efectos aparecen al cabo de varios años de exposición continuada a ruidos de más de $85 \mathrm{~dB}$. Por ello se recomienda como límite máximo de seguridad un nivel sonoro equivalente de $80 \mathrm{~dB}$. En cuanto a los efectos fisiológicos no auditivos afirma que se sabe con certeza que el ruido conlleva efectos negativos de tipo fisiológico que afectan a la visión, el estrés, la presión sanguínea, la tensión muscular y también, de tipo psicológico, provocando, por ejemplo, molestias, temor, perturbación de la actividad mental o física y del sueño [6, pp. 26-27]. Por lo tanto el sueño es de vital importancia para el rendimiento intelectual y una vida saludable, en cuanto a la importancia del ruido, como fuente de contaminación ambiental y su influencia sobre la calidad del sueńo, queda demostrada en los resultados de una encuesta realizada en el ańo 1989 a 263 adultos españoles, en la que se concluyó que nada menos que el 59\% tenía problemas de sueño, provocados por el ruido del tráfico, y el $49 \%$ se despertaba con frecuencia por este mismo motivo, [6, p.31]. También se afirma que las manifestaciones de las alteraciones psíquicas producidas por el ruido son múltiples: irritabilidad, astenia, susceptibilidad, agresividad, trastornos mentales, de la personalidad y del carácter. Pero tales efectos son simplemente los síntomas más preocupantes de una cadena que comienza con la disminución de la concentración, la inseguridad y la inquietud. A esto se suma también uno de los efectos más importantes del ruido, cual es el estrés o estado de tensión que repercute negativamente en la salud, provocando trastornos gastrointestinales y el aumento de la presión arterial [6, p. 29].

Los tres principales problemas de salud que puede generar el ruido, son: estrés, $44.1 \%$; insomnio, $15.5 \%$; y dolor de cabeza, $12.8 \%$. Las enfermedades de: hipertensión arterial, elevación del colesterol y azúcar, problemas gástricos, fatiga y ansiedad, son poco representativos como problema de salud 
generado por el ruido. Esto indica la escasa información que tiene el ciudadano sobre los efectos de ruido continuo a la salud humana [1, p.56]

La legislación nacional peruana ha desarrollado normas, para regular los ruidos a efectos de controlar la contaminación sonora, asignando obligaciones a los generadores de ruidos y vibraciones; así como disponiendo las atribuciones de fiscalización y sanción a cargo de las autoridades en los distintos niveles [7, p. 355], y la Ley General del Ambiente (Ley $\mathrm{N}^{\circ}$ 28611) dispone que en los distritos sean las autoridades las que establezcan las normas, su control y sanción, amparados en el reglamento de estándares nacionales de calidad ambiental para ruidos, y que con mucha claridad, son de aplicación porque están asociados a las zonas de aplicación, contemplando para ello zonas de protección especial (cerca a las instituciones educativas, centros de salud, albergues de ancianos, etc.), y también considerando los horarios nocturno y diurno, en nuestro caso, nuestra área de estudio de acuerdo al Decreto Supremo $\mathrm{N}^{\circ}$ 085-2003 Reglamento de los estándares nacionales de calidad ambiental para ruidos, a su ubicación le corresponde la clasificación de una zona de protección especial, correspondiéndoles en el horario diurno valores de $50 \mathrm{~dB}$ y en el horario nocturno $40 \mathrm{~dB}$; el Código Civil va más allá, prohíbe la emisión de ruidos que exceden la tolerancia, y el Código Penal reprime al que perturba a sus vecinos con discusiones, ruidos o molestias análogas [7, p. 356]. Entonces son varias la herramientas legales que protegen al ciudadano, pero esto conlleva una adecuada aplicación y sistemas de sensibilización, tanto para los que emiten y para los impactados por contaminación sonora. El vecino y el usuario de transporte público, debe ser consciente del daño producido y exigir al que emite el ruido su comprensión en las sociedades modernas, valerse de los medios visuales, de las redes sociales para llamar la atención, nos hemos percatado en los últimos tiempos, las grandes ventajas que poseen, porque van directamente a la mente a través de las imágenes, y por otro lado, la comunidad perjudicada debe exigir a la autoridad local que cumpla lo que la ley estipula, pero esta exigencia carece de evidencias, mientras no se instrumentalice.

Hay una consideración de mucha envergadura, a tener en cuenta y que tiene el respaldo legal y es lo referido al daño ambiental que está definido como toda pérdida, disminución, detrimento o menoscabo significativo inferido al ambiente o a uno o más de sus componentes, tales como el agua, suelos, aire, paisaje, flora, fauna, población, entre otros. El daño ambiental no solo consiste en la lesión al equilibrio ecológico sino también a otros valores vinculados como la calidad de vida y la salud de la colectividad. [...]. Así entonces el daño ambiental consistirá en un agresión directa al ambiente, que en forma indirecta puede provocar una lesión a la salud de las personas o afectación de su calidad de vida, de los que habitan la zona afectada. Se infiere que el daño ambiental en el caso de superar los niveles permitidos, estaría causando serios daños ambientales contemplados en la ley, como también los señala desde una perspectiva más pragmática el Tribunal Constitucional, que ha establecido que un ambiente puede ser afectado por alguna de estas cuatro actividades: a) Actividades molestas: son las que generan incomodidad por los ruidos o vibraciones, así como, por emanaciones de humos, gases, olores, nieblas o partículas en suspensión y otras sustancias. b) Actividades insalubres. C) Actividades nocivas y d) Actividades peligrosas [8, pp. 155-156].

El Organismo de Evaluación y Fiscalización Ambiental (OEFA) señala que la principal fuente generadora de la contaminación sonora, es el tránsito vehicular, debido al uso excesivo de bocinas en horas punta, siendo el mayor productor de contaminación sonora que tenemos en la ciudad.

Los sonidos de acuerdo a su intensidad producirán ondas mayores que los menos intensos, estas vibraciones dentro del oído pueden dañar las células ciliadas, el daño producido puede ser temporal, pero como esas células no se pueden reemplazar y presentan muy limitada capacidad para repararse, el daño continuará, para las personas que se exponen diariamente (...), debemos de sumar que anualmente millones de trabajadores industriales pierden proporciones importantes de capacidad auditiva por su exposición a ruidos intensos en sus lugares de trabajo [9, p. 643]. 
Los efectos no auditivos a más de $60 \mathrm{~dB}$, pueden provocar dilatación de las pupilas y parpadeo acelerado. Agitación respiratoria, aceleración del pulso y taquicardias. Aumento de la presión arterial y dolor de cabeza. Menor irrigación sanguínea y mayor actividad muscular. Los músculos se ponen tensos y dolorosos, sobre todo los del cuello y espalda. [9, p. 645].

La presente investigación tiene como objetivo general determinar la contaminación acústica que producen los vehículos de transporte público, los de transporte de carga, y los vehículos privados de uso personal, debajo del puente Benavides, tomando como referencia las horas en que existe mayor densidad vehicular, así como, las horas punta en horario diurno y nocturno, y así mismo determinar cómo esta contaminación impacta a los usuarios de ese paradero y a sus espacios aledaños. Generar conciencia en los alumnos de la Universidad Ricardo Palma acerca de esta problemática, que no solo causa efectos fisiológicos en la salud, a corto y largo plazo, sino que también puede afectar directa o indirectamente su desarrollo académico. El otro objetivo de la investigación es su contribución hacia la sociedad ya que se pretende generar el conocimiento de cómo se viene contaminando sonoramente a la comunidad aledaña al puente y brindar esta información de carácter científico a las autoridades municipales con el fin de motivar acciones para mitigar esta problemática contribuyendo a la formulación de actividades sensibilizadoras donde se beneficie a los no informados de este fenómeno y del impacto que está produciendo.

\section{MATERIALES Y MÉTODOS}

En el presente trabajo de investigación, se realizaron dos fases, en la primera de carácter exploratoria, con la realización de una encuesta apoyándonos en el diseño no experimental transeccional, y en una segunda fase se realizaron mediciones en el área del objetivo el puente de la avenida Benavides, apoyándonos en el diseño longitudinal, [10, p.187], en diferentes días y horarios, recogiendo datos y clasificándolos por horas de mayor concurrencia en el empleo de servicios de transporte público e incidencia de las presiones de ruido, especialmente a los producidos por las bocinas de los vehículos de transporte de carga pesada y el habitual transporte de pasajeros, además de los vehículos particulares. Esta área es concurrida por aquellos que usan estos espacios como paraderos, a los que se suman quienes realizan comercio ambulatorio y los denominados llenadores de camionetas y ómnibus, también se pudo contabilizar a los individuos que emplean este punto de embarque, en los distintos horarios, datos que servirían más adelante para clarificar las inferencias.

En la presente investigación, tomamos como objeto de estudio el paradero de Evitamiento del Puente Benavides, ubicado en el Distrito de Surco. Este se caracteriza por ser de intenso flujo vehicular y de bastante movimiento en los horarios de 7:00 a. m. a 9:00 a. m. y de 17:00 p. m. a 19:00 p. m., ya que se encuentra en el cruce de la Panamericana Sur y Av. Alfredo Benavides y por ser un área de empleo de la comunidad universitaria que utiliza este punto para trasladarse tanto al sur como al norte de la ciudad de Lima. La investigación de campo se extendió desde el día lunes 10 hasta el día viernes 14 de junio de 2019.

El trabajo de investigación longitudinal [10, p. 180], se realizó, haciendo la toma de datos a través de la medición por sonómetro denominado decibelímetro compacto UNI-T UT353, se grabó un aproximado de 20 minutos diarios en diferentes horarios y se eligieron las tres tomas con mayor nivel de ruido. De estas se escogieron el máximo y el mínimo grado de ruido. Este procedimiento, iniciado el día lunes 10 de junio, se repitió hasta el día viernes 14. Los resultados se organizaron en tablas para el mejor entendimiento de la realidad problemática.

Las encuestas realizadas a los alumnos de las Escuelas de Arquitectura e Ingeniería civil, estuvieron apoyados por un instrumento, el que constaba de 5 preguntas cerradas, el cual se aplicó a la muestra 
conformada por 151 individuos, elegidos de manera aleatoria, el diseño corresponde por lo tanto a una investigación no experimental, transeccional, ya que esta fase se realizó en un solo momento [10, p. 176]. Estas encuestas se realizaron a los alumnos y al personal administrativo de servicios, quienes laboran en los dos pabellones, la misma que fue en horarios diurnos y nocturnos, de la Universidad Ricardo Palma-., las Facultades de Ingeniería y Arquitectura, son las más expuestas a la contaminación sonora ya que los edificios colindan con la vía Panamericana Sur y hay un importante porcentaje de alumnos que emplean el paradero del puente de Benavides. Los datos obtenidos de las encuestas y haciendo empleo de las estadísticas descriptivas han servido para apoyar las respuestas de la investigación, las que se han presentado a manera de figuras y permitieron una clara explicación de los diferentes aspectos que contribuyeron, a clarificar los objetivos de trabajo, adjuntado los comentarios para una mayor comprensión de la realidad.

Esta investigación quiere hacer un llamado a las comunidades donde los actores, deben de regirse por normas de respeto mutuo preservando lo más vital, la vida, las realidades como éstas ocurren en cada parte de la ciudad, pero somos los actores los que debemos de concurrir, en un conjunto de puntos de coincidencias, la comunidad educativa tiene que llevar los aspectos metodológicos académicos a estudiar realidades de nuestro mundos cotidiano, donde los problemas están en el día a día, y poner a disposición de la sociedad este nuevo conocimiento evidenciándolo científicamente, hacer investigación aplicada y proponer correcciones y nuevas conductas. En el mundo globalizado hay sociedades que han superado a través de sus regulaciones estas dificultades. Hay una fuente inagotable de situaciones similares [10, pp. 701-702], por eso se cree que la ética, además de fundamentarse y de dotarse de una herramienta en la búsqueda de la verdad, debe apuntalarse en las razones del corazón que son las que nos van a mover a preferir unas cosas a otras y nos van a crear un vínculo imprescindible, entre lo que queremos hacer y lo que debemos hacer, un vínculo basado en el reconocimiento recíproco y en la lealtad entre los seres que son fines en sí mismos [11, p. 399].

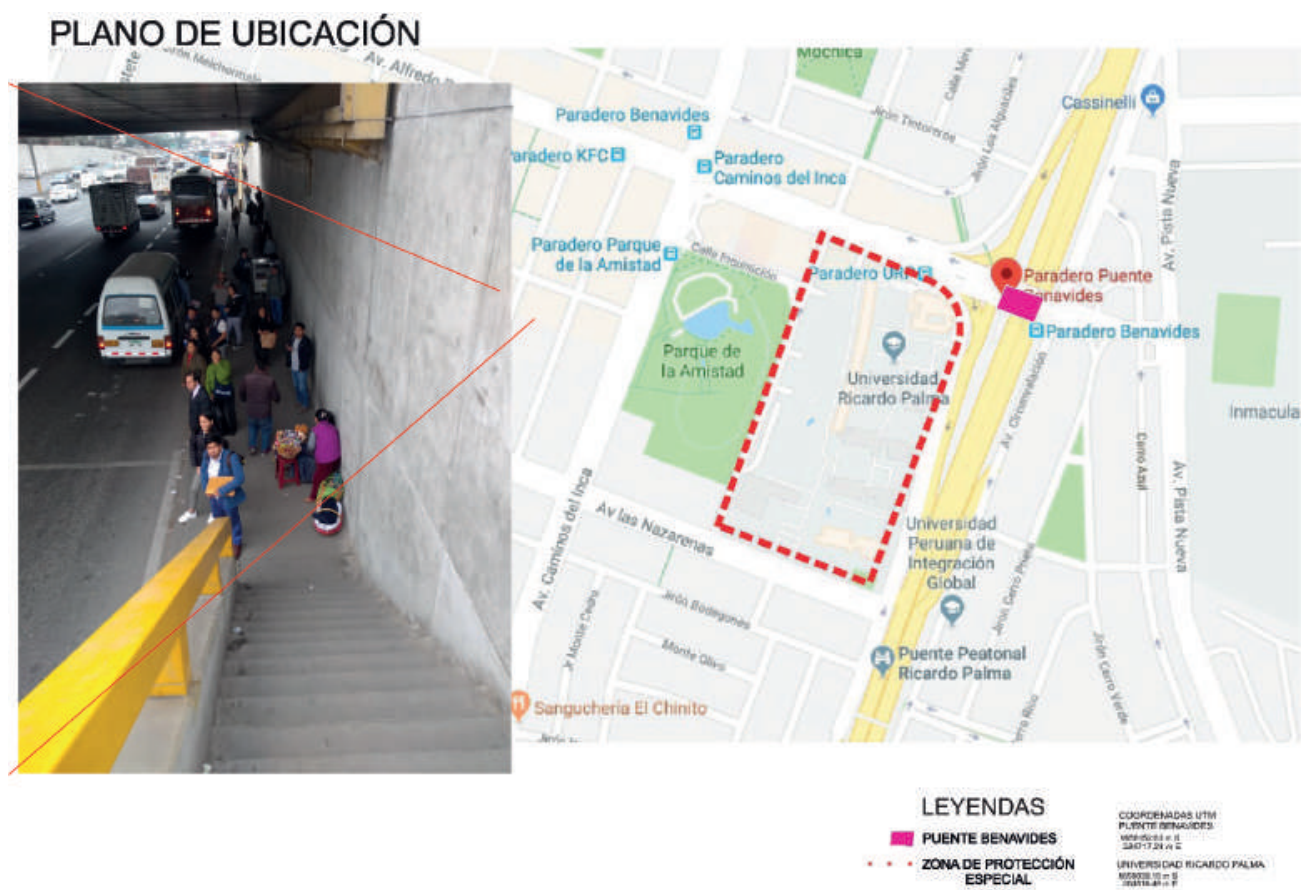

Figura 1. Plano de ubicación de la zona a realizar los estudios de investigación. Elaboración propia. 


\section{RESULTADOS}

Encuestas: Las encuestas se realizaron a una muestra de 151 personas de la Universidad Ricardo Palma, que fueron seleccionadas de manera aleatoria. Edad: se encuentra entre 17 años y 28 años; el promedio es de 20.5 años, la más frecuente es 21 ańos, y el 50\% de los encuestados tienen como mínimo 20 ańos. Sexo: el 38\% de los encuestados corresponde al sexo femenino y el $62 \%$ al masculino. Las preguntas más resaltantes fueron los siguientes:

1. De la pregunta Del 1 al 10, ¿Cuánto sabes de la contaminación sonora?, obtuvimos la siguiente figura:

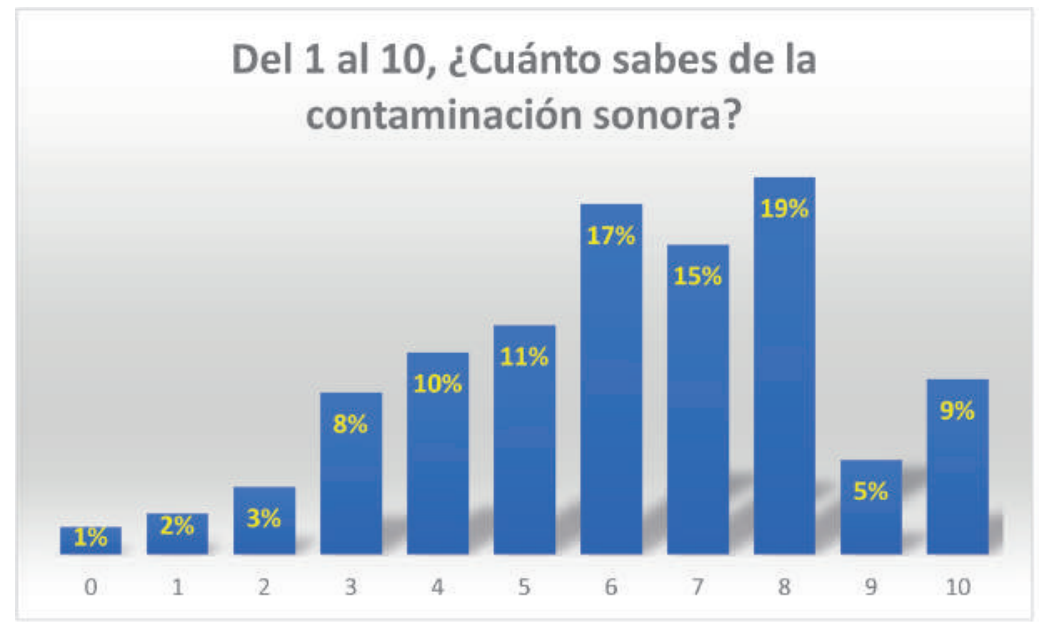

Figura 2. Resultados de la primera pregunta. Elaboración propia.

Comentario: como se observa en la figura, solo el $9 \%$ de los alumnos encuestados conocen el concepto de contaminación sonora y sus consecuencias, mientras que el 1\%, de los encuestados desconocen este concepto.

2. De la pregunta ¿Crees que el ruido causa malestares en la salud?, obtuvimos la siguiente figura:

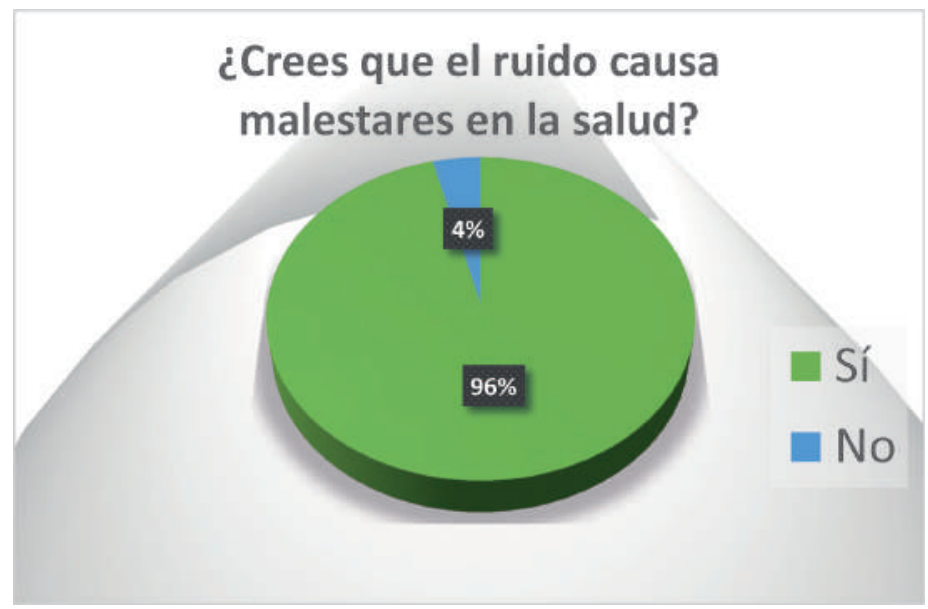

Figura 3. Resultados de la segunda pregunta. Elaboración propia. 
Comentario: el 96\% de los encuestados está consciente de la influencia de la contaminación sonora en su salud, mientras que un $4 \%$ aún no está informado sobre estos efectos.

3. De la pregunta ¿Si respondiste que Sí, qué malestares?, obtuvimos la siguiente figura:

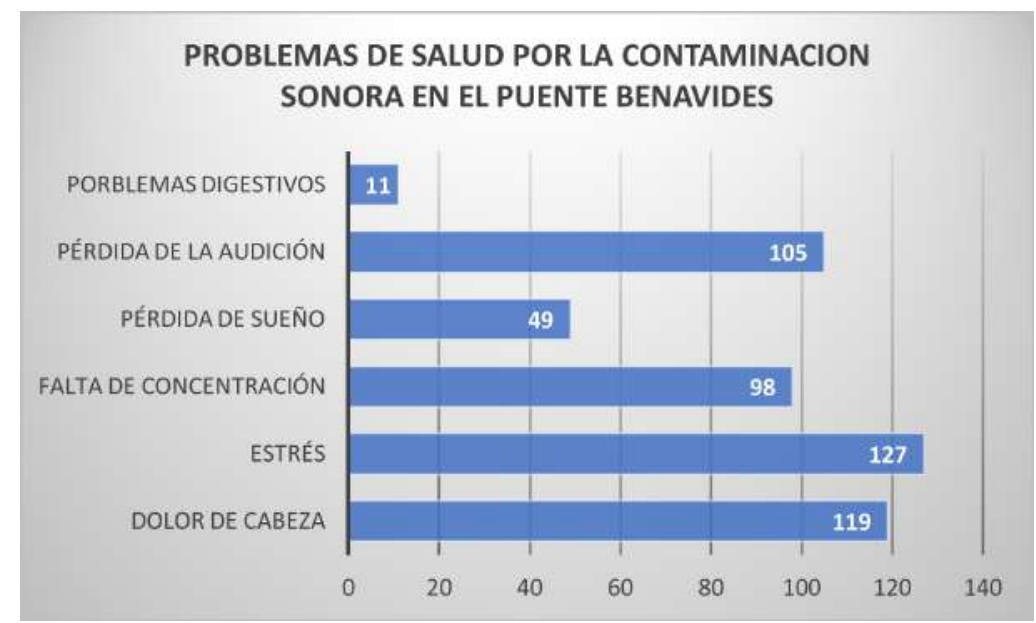

Figura 4. Resultados de la tercera pregunta. Elaboración propia.

Comentario: el $84.1 \%$ de los encuestados nombran el estrés como primer efecto causado por sonidos intensos en las personas. El 78.8\% de los encuestados nombran el dolor de cabeza como segundo efecto causado por sonidos intensos. El 69.5\% de las encuestas nombran a la pérdida de audición como el tercer efecto causado por sonidos intensos en personas.

4. De la pregunta ¿̨uál cree usted que es la mayor fuente de ruido en el sector?, obtuvimos la siguiente figura:

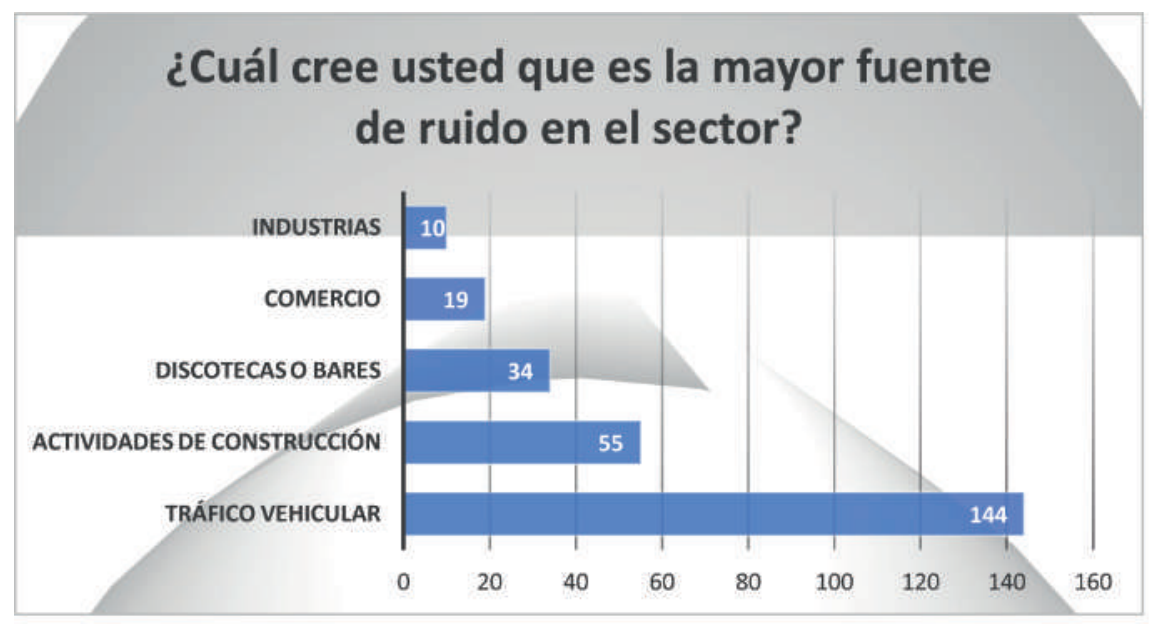

Figura 5. Resultados de la cuarta pregunta. Elaboración propia.

Comentario: de acuerdo con el resultado de las encuestas tomadas, el $90 \%$ de la muestra, cree que la mayor fuente de ruido en el sector es la producida por el tráfico vehicular. 
CIVIL

5. De la pregunta ¿Crees que la contaminación sonora afecta a los estudios?, obtuvimos la siguiente figura:

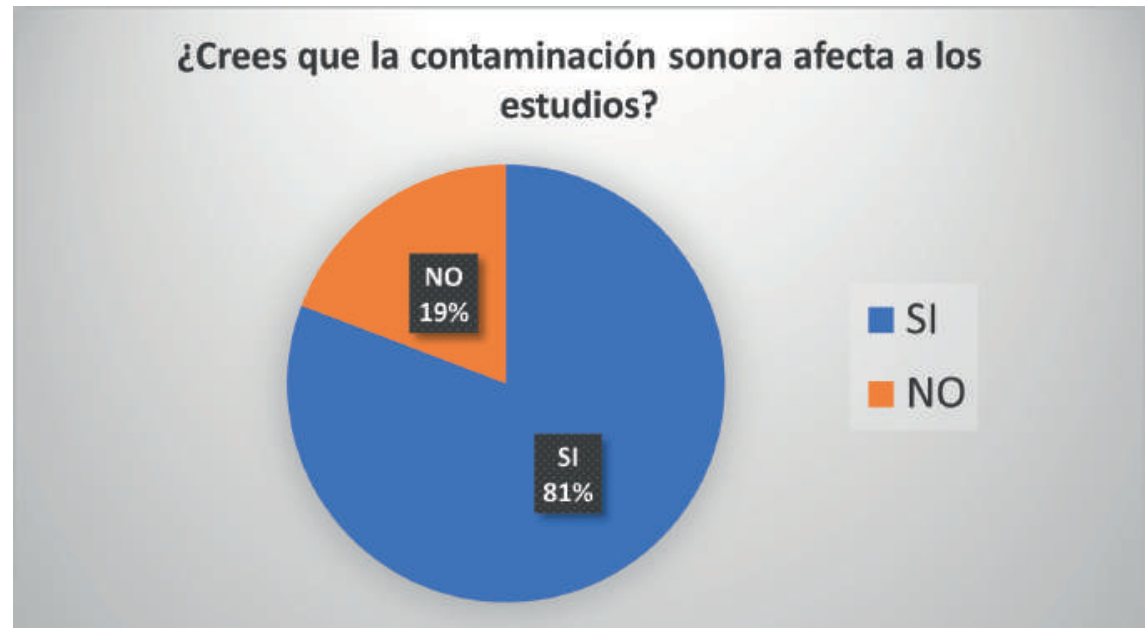

Figura 6. Resultados de la quinta pregunta. Elaboración propia.

Comentario: el 81\% de los encuestados afirma que la contaminación sonora influye de manera negativa en su desempeño académico. El 19\% de encuestados no sufre esta problemática.

Sonómetro: la toma de muestras con el sonómetro se realizó debajo del puente Benavides, cada 2 horas, por un tiempo de 10 minutos cada una, de lunes a viernes. Los resultados de esta se aprecian en la siguiente tabla:

Tabla 1. Resultados por horario, lunes.

\begin{tabular}{|c|c|c|c|c|c|c|c|c|c|}
\hline \multirow{2}{*}{ DIA } & \multirow{2}{*}{$\begin{array}{c}\text { Intervalo } \\
\text { (Hora) }\end{array}$} & \multirow{2}{*}{ Muestra } & \multirow{2}{*}{ Hora } & \multirow{2}{*}{$\begin{array}{c}\text { cantidad de } \\
\text { personas } \\
\text { afectadas }\end{array}$} & \multirow{2}{*}{$\begin{array}{c}\text { Decibeles } \\
\text { en } \\
\text { promedio }\end{array}$} & \multirow{2}{*}{ claxon (seg) } & \multirow{2}{*}{$\begin{array}{c}\text { Decibeles } \\
\text { con el } \\
\text { claxon } \\
\end{array}$} & \multicolumn{2}{|c|}{ Ddb con claxon } \\
\hline & & & & & & & & máx & $\min$ \\
\hline \multirow{3}{*}{$\begin{array}{l}\mathbf{L} \\
\mathbf{U}\end{array}$} & \multirow{3}{*}{$8: 00$ a $10: 00$} & \multirow{3}{*}{1} & 08:05 & 35 & 96.75 & 2 & 107.5 & \multirow{3}{*}{107.5} & \multirow{3}{*}{104.2} \\
\hline & & & $08: 10$ & 42 & 95.65 & 2 & 105.3 & & \\
\hline & & & 09:45 & 22 & 95.1 & 3 & 104.2 & & \\
\hline $\mathbf{N}$ & \multirow{3}{*}{$10: 00$ a $12: 00$} & \multirow{3}{*}{2} & $10: 10$ & 18 & 95.7 & 2 & 105.4 & \multirow{3}{*}{105.4} & \multirow{3}{*}{102.8} \\
\hline$E$ & & & $11: 20$ & 20 & 94.4 & 2 & 102.8 & & \\
\hline \multirow[t]{2}{*}{$\mathbf{S}$} & & & $11: 40$ & 23 & 95.15 & 3 & 104.3 & & \\
\hline & \multirow{3}{*}{$12: 00$ a $14: 00$} & \multirow{3}{*}{3} & $12: 10$ & 15 & 95.55 & 2 & 105.1 & \multirow{3}{*}{105.1} & \multirow{3}{*}{102.6} \\
\hline 1 & & & $13: 42$ & 17 & 94.65 & 2 & 103.3 & & \\
\hline \multirow[t]{2}{*}{0} & & & $13: 50$ & 15 & 94.3 & 3 & 102.6 & & \\
\hline & \multirow{3}{*}{$14: 00$ a $16: 00$} & \multirow{3}{*}{4} & $14: 00$ & 13 & 95 & 2 & 104 & \multirow{3}{*}{106.4} & \multirow{3}{*}{103.6} \\
\hline 0 & & & $14: 50$ & 16 & 94.8 & 4 & 103.6 & & \\
\hline \multirow[t]{2}{*}{6} & & & $15: 22$ & 20 & 96.2 & 3 & 106.4 & & \\
\hline & \multirow{3}{*}{$16: 00$ a $18: 00$} & \multirow{3}{*}{5} & $16: 30$ & 19 & 96.8 & 2 & 107.6 & \multirow{3}{*}{108.7} & \multirow{3}{*}{106.5} \\
\hline \multirow{5}{*}{$\begin{array}{l}2 \\
0 \\
1 \\
9\end{array}$} & & & $16: 40$ & 20 & 97.35 & 5 & 108.7 & & \\
\hline & & & $17: 10$ & 32 & 96.25 & 2 & 106.5 & & \\
\hline & & & $18: 05$ & 45 & 96.2 & 2 & 106.4 & & \\
\hline & $18: 00$ a $20: 00$ & 6 & $18: 35$ & 55 & 95.25 & 2 & 104.5 & 107.1 & 104.5 \\
\hline & & & $18: 45$ & 61 & 96.55 & 3 & 107.1 & & \\
\hline
\end{tabular}

Elaboración propia. 


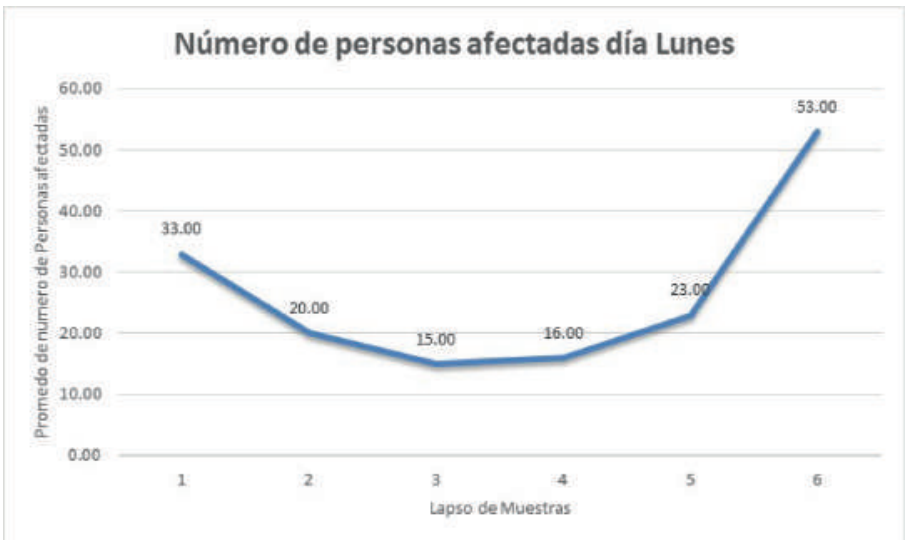

Figura 7. Personas afectadas el lunes. Elaboración propia.

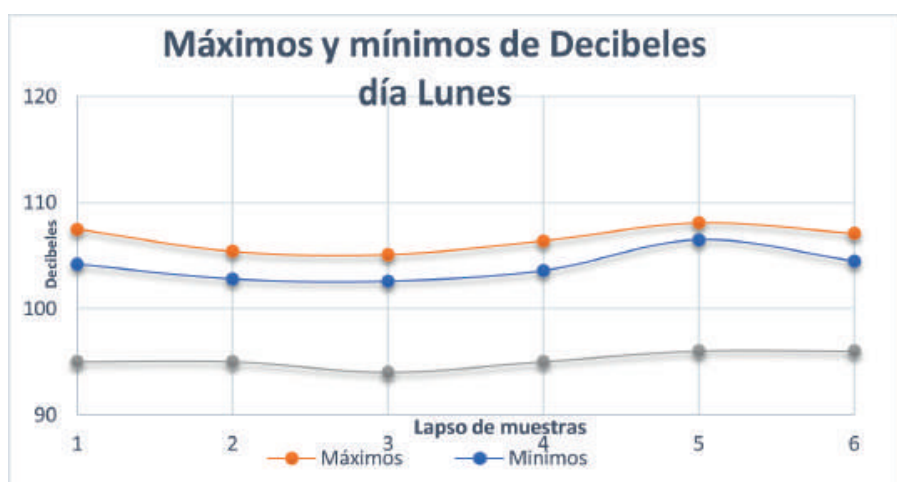

Figura 8. Máximos y minimos del lunes. Elaboración propia.

Tabla 2. Resultados por horario, martes.

\begin{tabular}{|c|c|c|c|c|c|c|c|c|c|}
\hline \multirow{2}{*}{ DIA } & \multirow{2}{*}{$\begin{array}{c}\text { Intervalo } \\
\text { (Hora) }\end{array}$} & \multirow{2}{*}{ Muestra } & \multirow{2}{*}{ Hora } & \multirow{2}{*}{\begin{tabular}{c|} 
cantidad de \\
personas \\
afectadas
\end{tabular}} & \multirow{2}{*}{$\begin{array}{c}\text { Decibeles } \\
\text { en } \\
\text { promedio }\end{array}$} & \multirow{2}{*}{ claxon (seg) } & \multirow{2}{*}{$\begin{array}{c}\text { Decibeles } \\
\text { con el } \\
\text { claxon } \\
\end{array}$} & \multicolumn{2}{|c|}{ Ddb con claxon } \\
\hline & & & & & & & & máx & $\min$ \\
\hline \multirow{2}{*}{$\begin{array}{l}M \\
A\end{array}$} & \multirow{3}{*}{$8: 00$ a $10: 00$} & \multirow{3}{*}{7} & 08:08 & 30 & 96.4 & 3 & 106.8 & \multirow{3}{*}{107.6} & \multirow{3}{*}{106.8} \\
\hline & & & 08:33 & 36 & 96.75 & 3 & 107.5 & & \\
\hline \multirow{2}{*}{$\begin{array}{l}\mathrm{R} \\
\mathrm{T}\end{array}$} & & & $09: 16$ & 26 & 96.8 & 4 & 107.6 & & \\
\hline & \multirow{3}{*}{$10: 00$ a $12: 00$} & \multirow{3}{*}{8} & $10: 00$ & 15 & 95 & 2 & 104 & \multirow{3}{*}{105} & \multirow{3}{*}{102} \\
\hline \multirow{3}{*}{$\begin{array}{l}E \\
S\end{array}$} & & & $10: 22$ & 12 & 94 & 3 & 102 & & \\
\hline & & & $11: 30$ & 11 & 95.5 & 2 & 105 & & \\
\hline & \multirow{3}{*}{$12: 00$ a $14: 00$} & \multirow{3}{*}{9} & $12: 00$ & 8 & 95.3 & 2 & 104.6 & \multirow{3}{*}{104.6} & \multirow{3}{*}{103.6} \\
\hline \multirow{3}{*}{$\begin{array}{l}1 \\
1\end{array}$} & & & $13: 15$ & 12 & 94.8 & 2 & 103.6 & & \\
\hline & & & $13: 35$ & 15 & 95.05 & 3 & 104.1 & & \\
\hline & \multirow{3}{*}{$14: 00$ a $16: 00$} & \multirow{3}{*}{10} & $14: 20$ & 17 & 95.25 & 5 & 104.5 & \multirow{3}{*}{106.9} & \multirow{3}{*}{98.9} \\
\hline \multirow{3}{*}{$\begin{array}{l}0 \\
6\end{array}$} & & & $14: 32$ & 20 & 92.45 & 4 & 98.9 & & \\
\hline & & & $15: 10$ & 23 & 96.45 & 1 & 106.9 & & \\
\hline & \multirow{3}{*}{$16: 00$ a $18: 00$} & \multirow{3}{*}{11} & 16:05 & 26 & 96.9 & 2 & 107.8 & \multirow{3}{*}{107.8} & \multirow{3}{*}{105.7} \\
\hline & & & $16: 08$ & 31 & 95.85 & 1 & 105.7 & & \\
\hline $\begin{array}{l}2 \\
0\end{array}$ & & & $16: 20$ & 39 & 96.15 & 2 & 106.3 & & \\
\hline 1 & & & $18: 00$ & 42 & 96.9 & 2 & 107.8 & & \\
\hline 1 & $18: 00$ a $20: 00$ & 12 & $18: 05$ & 50 & 96.4 & 3 & 106.8 & 108.6 & 106.8 \\
\hline 9 & & & 19:25 & 52 & 97.3 & 2 & 108.6 & & \\
\hline
\end{tabular}

Elaboración propia. 


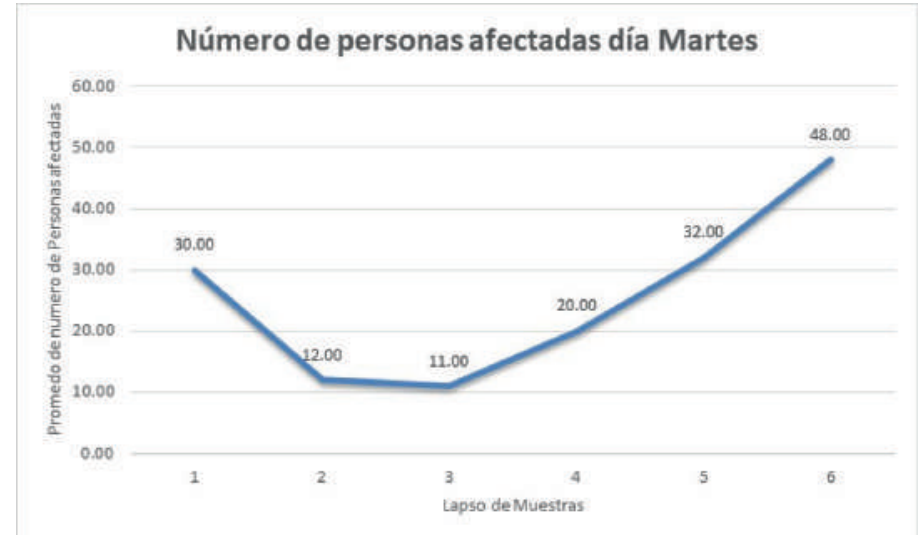

Figura 9. Personas afectadas el martes. Elaboración propia.

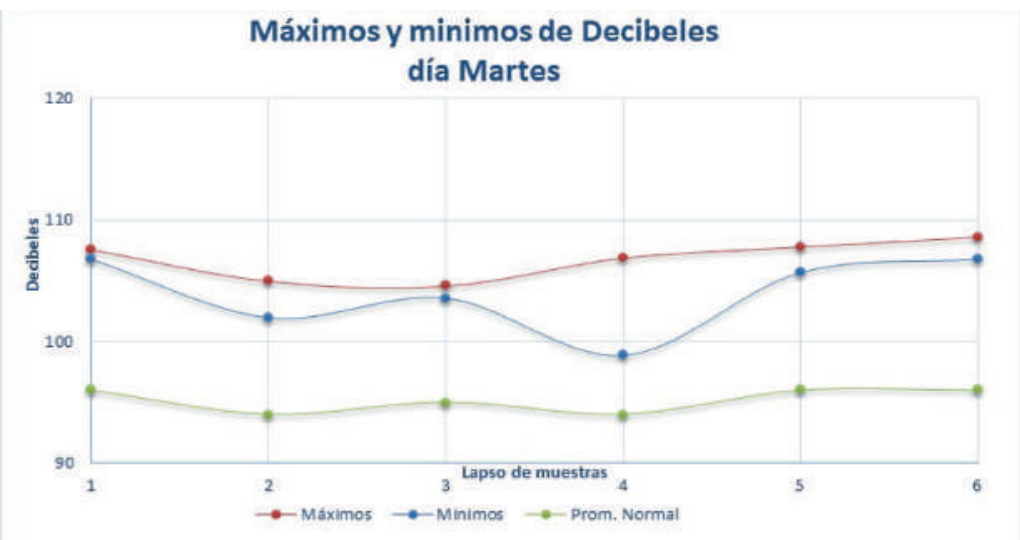

Figura 10. Máximos y minimos del martes. Elaboración propia.

Tabla 3. Resultados por horario, miércoles.

\begin{tabular}{|c|c|c|c|c|c|c|c|c|c|}
\hline \multirow{2}{*}{ DIA } & \multirow{2}{*}{$\begin{array}{c}\text { Intervalo } \\
\text { (Hora) }\end{array}$} & \multirow{2}{*}{ Muestra } & \multirow{2}{*}{ Hora } & \multirow{2}{*}{$\begin{array}{c}\text { cantidad de } \\
\text { personas } \\
\text { afectadas }\end{array}$} & \multirow{2}{*}{$\begin{array}{c}\text { Decibeles } \\
\text { en } \\
\text { promedio }\end{array}$} & \multirow{2}{*}{ claxon (seg) } & \multirow{2}{*}{$\begin{array}{c}\text { Decibeles } \\
\text { con el } \\
\text { claxon }\end{array}$} & \multicolumn{2}{|c|}{ Ddb con claxon } \\
\hline & & & & & & & & máx & $\min$ \\
\hline \multirow{2}{*}{$\begin{array}{c}M \\
1\end{array}$} & \multirow{3}{*}{$8: 00$ a $10: 00$} & \multirow{3}{*}{13} & 08:01 & 40 & 95.15 & 3 & 104.3 & \multirow{3}{*}{106.8} & \multirow{3}{*}{104.3} \\
\hline & & & 08:05 & 44 & 96.4 & 3 & 106.8 & & \\
\hline $\mathrm{E}$ & & & 09:10 & 17 & 95.25 & 2 & 104.5 & & \\
\hline R & \multirow{3}{*}{$10: 00$ a $12: 00$} & \multirow{3}{*}{14} & $10: 00$ & 19 & 94 & 4 & 102 & \multirow{3}{*}{104} & \multirow{3}{*}{99} \\
\hline \multirow{2}{*}{$\begin{array}{l}\text { C } \\
\text { o }\end{array}$} & & & 10:07 & 11 & 95 & 6 & 104 & & \\
\hline & & & $11: 50$ & 15 & 92.5 & 5 & 99 & & \\
\hline $\mathrm{E}$ & \multirow{3}{*}{$12: 00$ a $14: 00$} & \multirow{3}{*}{15} & $12: 30$ & 16 & 95.05 & 2 & 104.1 & \multirow{3}{*}{105.3} & \multirow{3}{*}{103.2} \\
\hline \multirow[t]{2}{*}{$\mathrm{s}$} & & & $12: 40$ & 29 & 95.65 & 2 & 105.3 & & \\
\hline & & & $13: 40$ & 21 & 94.6 & 3 & 103.2 & & \\
\hline 1 & \multirow{3}{*}{$14: 00$ a $16: 00$} & \multirow{3}{*}{16} & $14: 03$ & 26 & 94.6 & 5 & 103.2 & \multirow{3}{*}{107.2} & \multirow{3}{*}{103.2} \\
\hline 2 & & & $14: 15$ & 20 & 94.9 & 2 & 103.8 & & \\
\hline \multirow{3}{*}{$\begin{array}{l}0 \\
6\end{array}$} & & & $15: 20$ & 27 & 96.6 & 2 & 107.2 & & \\
\hline & \multirow{3}{*}{$16: 00$ a $18: 00$} & \multirow{3}{*}{17} & $16: 04$ & 31 & 96.45 & 2 & 106.9 & \multirow{3}{*}{108.4} & \multirow{3}{*}{106.9} \\
\hline & & & $16: 10$ & 36 & 97.2 & 1 & 108.4 & & \\
\hline 2 & & & 17:08 & 39 & 97.1 & 4 & 108.2 & & \\
\hline 0 & & & 18:08 & 45 & 96.15 & 2 & 106.3 & & \\
\hline 1 & $18: 00$ a $20: 00$ & 18 & 18:15 & 51 & 97.35 & 2 & 108.7 & 108.7 & 106.3 \\
\hline & & & $18: 22$ & 62 & 96.55 & 2 & 107.1 & & \\
\hline
\end{tabular}

Elaboración propia. 


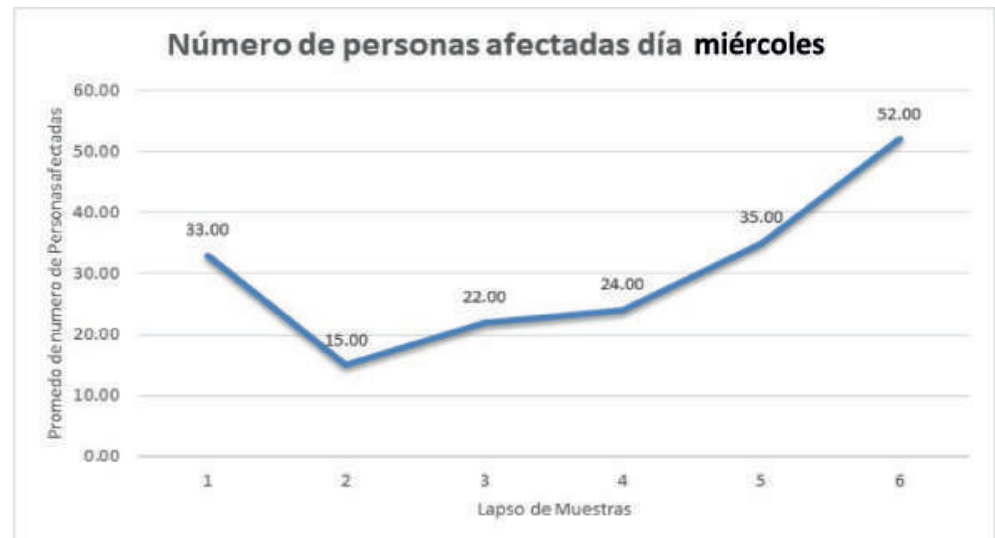

Figura 11. Personas afectadas del miércoles. Elaboración propia.

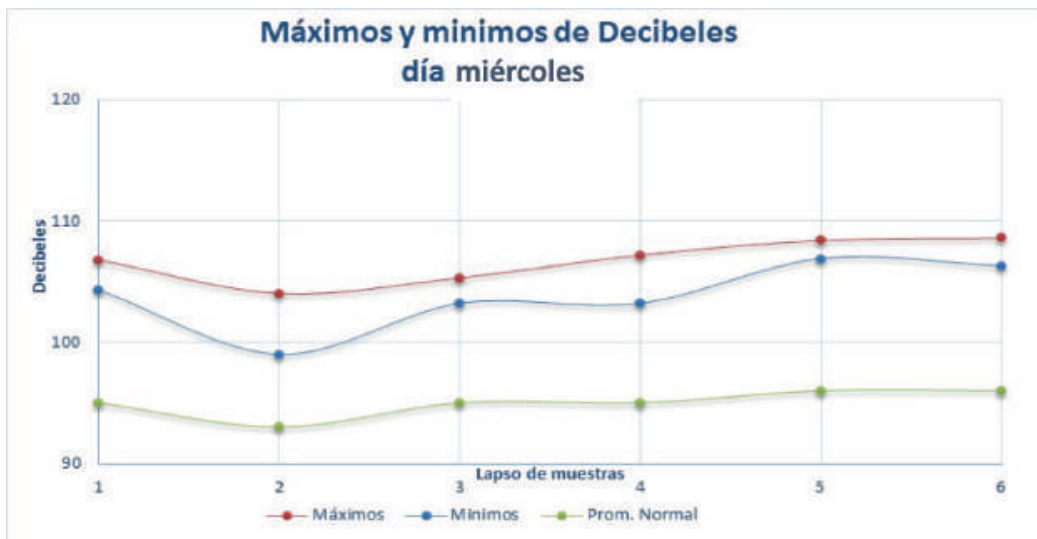

Figura 12. Máximos y Minimos del miércoles. Elaboración propia.

Tabla 4. Resultados por horario, jueves.

\begin{tabular}{|c|c|c|c|c|c|c|c|c|c|}
\hline \multirow[b]{2}{*}{ DIA } & \multirow{2}{*}{$\begin{array}{c}\text { Intervalo } \\
\text { (Hora) }\end{array}$} & \multirow{2}{*}{ Muestra } & \multirow{2}{*}{ Hora } & \multirow{2}{*}{$\begin{array}{l}\text { cantidad de } \\
\text { personas } \\
\text { afectadas }\end{array}$} & \multirow{2}{*}{$\begin{array}{c}\text { Decibeles } \\
\text { en } \\
\text { promedio }\end{array}$} & \multirow[b]{2}{*}{ claxon (seg) } & \multirow{2}{*}{$\begin{array}{l}\text { Decibeles } \\
\text { con el } \\
\text { claxon }\end{array}$} & \multicolumn{2}{|c|}{ Ddb con claxon } \\
\hline & & & & & & & & máx & $\min$ \\
\hline \multirow{2}{*}{$\begin{array}{l}\mathrm{J} \\
\mathrm{U}\end{array}$} & \multirow{3}{*}{$8: 00$ a $10: 00$} & \multirow{3}{*}{19} & $08: 30$ & 36 & 95.15 & 3 & 104.3 & \multirow{3}{*}{106.6} & \multirow{3}{*}{104.2} \\
\hline & & & $08: 35$ & 42 & 96.3 & 2 & 106.6 & & \\
\hline \multirow[t]{2}{*}{$\mathrm{E}$} & & & 09:02 & 26 & 95.1 & 2 & 104.2 & & \\
\hline & \multirow{3}{*}{$10: 00$ a $12: 00$} & \multirow{3}{*}{20} & $10: 40$ & 13 & 94.7 & 2 & 103.4 & \multirow{3}{*}{104.3} & \multirow{3}{*}{102} \\
\hline \multirow[t]{2}{*}{$E$} & & & $10: 52$ & 9 & 94 & 2 & 102 & & \\
\hline & & & 11:02 & 12 & 95.15 & 2 & 104.3 & & \\
\hline $\mathrm{S}$ & \multirow{3}{*}{$12: 00$ a $14: 00$} & \multirow{3}{*}{21} & $13: 35$ & 20 & 95.65 & 3 & 105.3 & \multirow{3}{*}{105.3} & \multirow{3}{*}{103.6} \\
\hline \multirow{3}{*}{$\begin{array}{l}1 \\
3\end{array}$} & & & $13: 38$ & 22 & 95.25 & 4 & 104.5 & & \\
\hline & & & $13: 40$ & 26 & 94.8 & 3 & 103.6 & & \\
\hline & \multirow{3}{*}{$14: 00$ a $16: 00$} & \multirow{3}{*}{22} & $14: 40$ & 22 & 95.25 & 3 & 104.5 & \multirow{3}{*}{106.9} & \multirow{3}{*}{104.5} \\
\hline \multirow{3}{*}{$\begin{array}{l}0 \\
6\end{array}$} & & & $14: 46$ & 12 & 96.05 & 2 & 106.1 & & \\
\hline & & & $14: 50$ & 18 & 96.45 & 2 & 106.9 & & \\
\hline & \multirow{3}{*}{$16: 00$ a $18: 00$} & \multirow{3}{*}{23} & $17: 35$ & 26 & 95.9 & 3 & 105.8 & \multirow{3}{*}{108.6} & \\
\hline & & & $17: 39$ & 24 & 96.9 & 4 & 107.8 & & 105.8 \\
\hline $\begin{array}{l}2 \\
0\end{array}$ & & & $17: 55$ & 32 & 97.3 & 3 & 108.6 & & \\
\hline 0 & & & $18: 02$ & 40 & 95.65 & 2 & 105.3 & & \\
\hline 1 & $18: 00$ a $20: 00$ & 24 & $18: 08$ & 45 & 96.6 & 2 & 107.2 & 107.2 & 105.3 \\
\hline & & & 19:50 & 35 & 96.4 & 3 & 106.8 & & \\
\hline
\end{tabular}

Elaboración propia. 


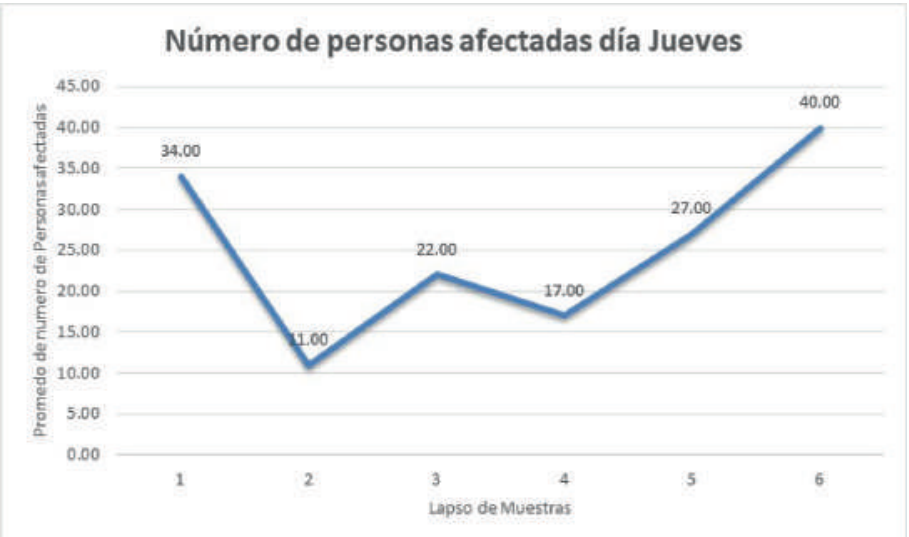

Figura 13. Personas afectadas del jueves. Elaboración propia.

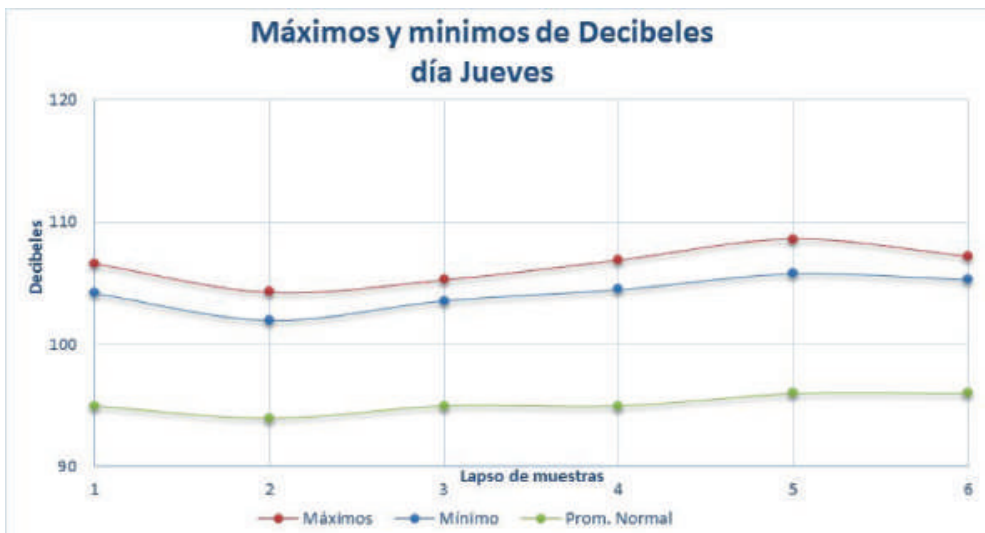

Figura 14. Máximos y minimos del jueves. Elaboración propia.

Tabla 5. Resultados por horario, viernes.

\begin{tabular}{|c|c|c|c|c|c|c|c|c|c|}
\hline \multirow{2}{*}{ DIA } & \multirow{2}{*}{$\begin{array}{c}\text { Intervalo } \\
\text { (Hora) }\end{array}$} & \multirow{2}{*}{ Muestra } & \multirow{2}{*}{ Hora } & \multirow{2}{*}{\begin{tabular}{|c|} 
cantidad de \\
personas \\
afectadas
\end{tabular}} & \multirow{2}{*}{$\begin{array}{c}\text { Decibeles } \\
\text { en } \\
\text { promedio }\end{array}$} & \multirow{2}{*}{ claxon (seg) } & \multirow{2}{*}{$\begin{array}{c}\text { Decibeles } \\
\text { con el } \\
\text { claxon }\end{array}$} & \multicolumn{2}{|c|}{ Ddb con claxon } \\
\hline & & & & & & & & máx & $\min$ \\
\hline V & \multirow{3}{*}{$8: 00$ a $10: 00$} & \multirow{3}{*}{25} & 08:07 & 30 & 95.65 & 2 & 105.3 & \multirow{3}{*}{105.3} & \multirow{3}{*}{102.6} \\
\hline 1 & & & 08:11 & 35 & 94.3 & 3 & 102.6 & & \\
\hline$E$ & & & $08: 26$ & 36 & 95.2 & 2 & 104.4 & & \\
\hline $\mathrm{R}$ & \multirow{3}{*}{$10: 00$ a $12: 00$} & \multirow{3}{*}{26} & $10: 36$ & 25 & 93.7 & 2 & 101.4 & \multirow{3}{*}{104.3} & \multirow{3}{*}{101.4} \\
\hline $\mathrm{N}$ & & & $10: 52$ & 16 & 94 & 1 & 102 & & \\
\hline$E$ & & & $11: 21$ & 18 & 95.15 & 2 & 104.3 & & \\
\hline \multirow[t]{2}{*}{ s } & \multirow{3}{*}{$12: 00$ a $14: 00$} & \multirow{3}{*}{27} & $12: 00$ & 15 & 95.1 & 2 & 104.2 & \multirow{3}{*}{105.8} & \multirow{3}{*}{104.2} \\
\hline & & & $12: 04$ & 18 & 95.7 & 2 & 105.4 & & \\
\hline \multirow{3}{*}{$\begin{array}{l}1 \\
4\end{array}$} & & & $12: 20$ & 16 & 95.9 & 3 & 105.8 & & \\
\hline & \multirow{3}{*}{$14: 00$ a $16: 00$} & \multirow{3}{*}{28} & $14: 30$ & 21 & 96.4 & 1 & 106.8 & \multirow{3}{*}{107.1} & \multirow{3}{*}{105.8} \\
\hline & & & $14: 36$ & 19 & 95.9 & 4 & 105.8 & & \\
\hline \multirow{3}{*}{$\begin{array}{l}0 \\
6\end{array}$} & & & $15: 15$ & 25 & 96.55 & 2 & 107.1 & & \\
\hline & \multirow{3}{*}{$16: 00$ a $18: 00$} & \multirow{3}{*}{29} & 16:00 & 20 & 96.15 & 3 & 106.3 & \multirow{3}{*}{108.4} & \multirow{3}{*}{106.3} \\
\hline & & & $16: 12$ & 24 & 96.75 & 2 & 107.5 & & \\
\hline 2 & & & $16: 32$ & 40 & 97.2 & 2 & 108.4 & & \\
\hline 0 & \multirow{3}{*}{$18: 00$ a $20: 00$} & \multirow{3}{*}{30} & $18: 00$ & 48 & 97.15 & 2 & 108.3 & & \\
\hline 1 & & & $18: 30$ & 56 & 97.65 & 3 & 109.3 & 109.3 & 106.6 \\
\hline 9 & & & 19:10 & 59 & 96.3 & 13 & 106.6 & & \\
\hline
\end{tabular}

Elaboración propia. 


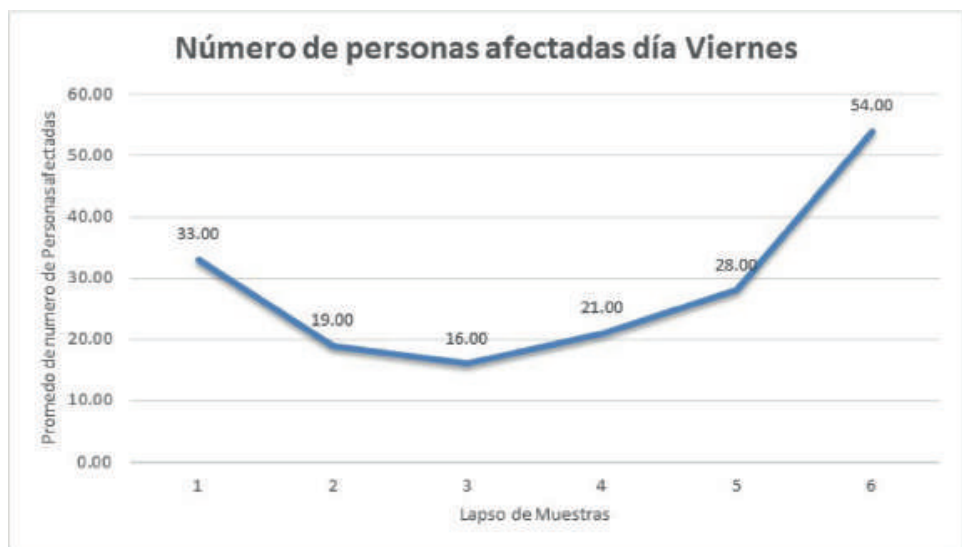

Figura 15. Personas afectadas el viernes. Elaboración propia.

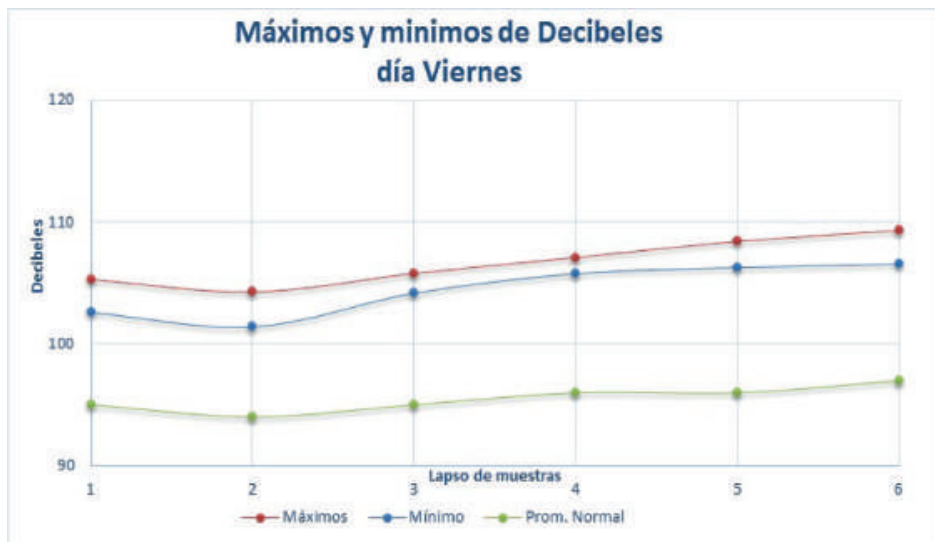

Figura 16. Máximos y mínimos del viernes. Elaboración propia.

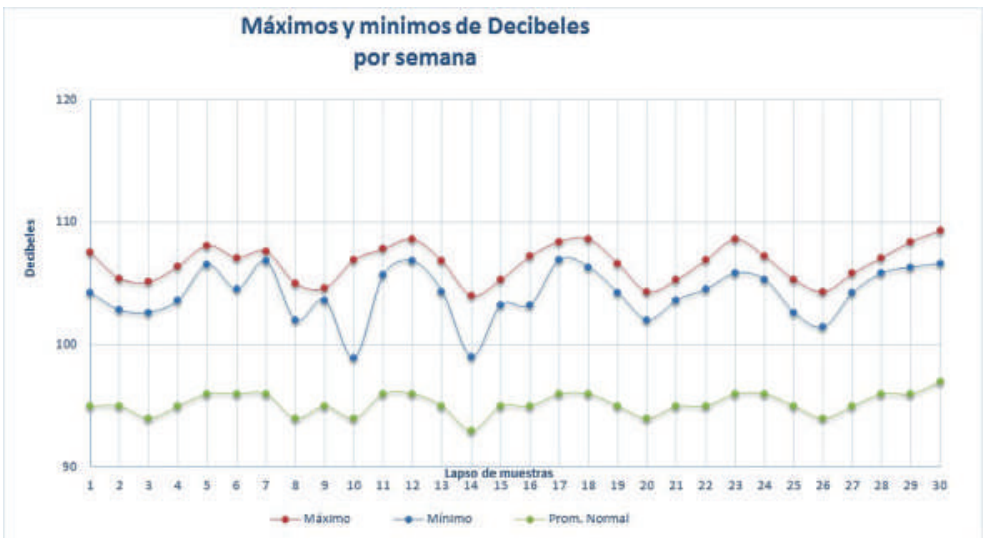

Figura 17. Máximos y minimos de la semana. Elaboración propia.

Analizando los resultados de los datos promedio obtenidos, con los registros recogidos por el sonómetro, los niveles de ruido en el paradero del puente Benavides, superaron el doble del nivel 
permitido en el horario diurno en la mayoría de los registros. Dado que se trata de un punto central de concurrencia para muchas personas y también ello sustenta las afirmaciones recogidas de los datos de las encuestas.

\section{DISCUSIÓN}

A través de los resultados, se puede evidenciar los altos nivel de ruido producido en el paradero del puente Benavides, objeto de estudio. Es de suma importancia concientizar a los afectados, a los causantes de ruido y a las autoridades, responsables de cuidar al ciudadano, sobre este problema. El hallazgo más importante se registró el día viernes 14 de junio de 2019 a las 18:30 hrs., donde se recibió durante 3 segundos 109.3 dB. En los 90 registros solo uno de ellos estuvo por debajo de los $100 \mathrm{~dB}$. Lo que demuestra los altos niveles de contaminación sonora que están impactando en aquellos que emplean este importante paradero que conecta a la ciudad en la Vía de Evitamiento y la avenida Benavides. Los registros evidencian y confirman que estas cifras colisionan todos los aspectos referentes a la normatividad existente, el desconocimiento de los conductores del daño ambiental que están provocando y las sanciones a las que podrían aplicárseles, así también, la falta de Control de la Autoridad Municipal en esta zona de importancia vital para los usuarios que acceden a los medios de transporte público, sin medida que los protejan adecuadamente del daño ambiental a que están siendo expuestos, causado por la contaminación sonora, ya que el ruido les causa daños fisiológicos y no fisiológicos.

Con esta investigación, se ha llegado a evidenciar la alerta necesaria para poder tomar un conjunto de acciones que estén de acuerdo con lo estipulado en el Decreto Supremo N. o 085-2003-PCM, Reglamento de Estándares Nacionales de Calidad Ambiental para Ruido, que establece, en su Artículo 4, «De los Estándares Primarios de Calidad Ambiental para Ruido», que los niveles máximos de ruido en el ambiente no deben excederse, de forma que se proteja la salud humana. Como se observó en los datos tomados, se presenta un nivel indeseable en la zona debajo del puente Benavides, paradero vehicular que es empleado por muchos de los estudiantes de nuestra casa de estudios.

El incremento de las concentraciones poblacionales en las urbes, y la densificación de ciertos espacios, particularmente los paraderos del Transporte Público, ocasionan que los ruidos perjudiciales se presenten comúnmente en el día a día, aunque este tema pase desapercibido en los jóvenes, ya que los daños se apreciarán con el transcurrir de los años, aunque si hay efectos inmediatos como son el stress, los dolores de cabeza y el incremento de la presión arterial, los que van a influir en la falta de concentración. Sin embargo, contándose con, una amplia legislación ambiental, la pregunta es si la misma se llega a cumplir, para lo cual sería conveniente que los principales puntos de la ciudad se tuvieran seńalizados los niveles de contaminación aceptables de manera que el usuario tendría elementos para protegerse y para exigir el cumplimiento de la ley.

En cuanto a los resultados de las encuestas realizadas a los alumnos de la URP, se pudo observar la falta de información en este tema, ya que, si bien es cierto que la mayoría son conscientes de los efectos nocivos que los altos niveles de ruido generan en su salud, no se presentan iniciativas para solucionar esta problemática, ya que la pasividad se ha convertido en parte de la cultura ciudadana. Esto se observa en el hecho de que aún no existen campañas de alerta sobre los graves daños a la salud a los que están expuestas las personas, este elemento podría cambiar la actitud tanto de los que contaminan, como los impactados sonoramente. Por otro lado, hay una inacción absoluta tanto de parte de la autoridad municipal como del gobierno central para proteger a los ciudadanos. Este ruido, que forma parte de la contaminación acústica o sonora, diariamente daña la salud de los que utilizan dicho espacio público. Así mismo, los choferes de transporte público y privado, que emplean el claxon de manera irresponsable, son insensibles y realizan estos ruidos molestos, sin ningún reparo. 
La ciudad sigue creciendo, el transporte público tiene que seguir buscando satisfacer las necesidades de transporte, modernizando no solo sus unidades, sino particularmente, se debe capacitar a los choferes o conductores porque son ellos los primeros perjudicados e impactados ambientalmente, y por su parte las autoridades deberían dar la mayor importancia a esta problemática.

En el presente trabajo investigativo hemos referenciado estudios e investigaciones anteriores, que datan hace más de una década con registros similares a los hallados en este estudio, siendo muy poco lo que se ha hecho hasta el presente. Es necesario que las autoridades responsables respondan con mecanismos de control y sensibilización tomando medidas para poder solucionar este problema, pues la Universidad Ricardo Palma, se ubica en una zona de protección especial, muy próxima al área objeto de $\mathrm{n}$ la presente investigación, con gran concurrencia de sus alumnos.

\section{REFERENCIAS BIBLIOGRÁFICAS}

[1] I. Solís, Influencia de la Contaminación sonora en la salud pública, del poblador del Cercado de Lima. Revista Paideia XXI. Vol. 3 N4, Lima, diciembre 2013, pp.47-59. Disponible en : file://C:/ Users/User/Downloads/926-Texto\%20del\%20art\%C3\%ADculo-2038-1-10-20170918\%20 (2).pdf [Accedido el 17 marzo 2020].

[2] M. Alfie y O. Salinas, Ruido en la ciudad. Contaminación auditiva y ciudad contaminable. Revista Estudios Demográficos urbanos. Vol. 32, №1 (94) 2017. Disponible en: http://www.scielo.org. mx/pdf/educm/v32n1/2448-6515-educm-32-01-00065.pdf [ Accedido el 17 marzo 2020].

[3] J. Martínez y J. Peters, Contaminación acuistica y ruido. 3ra Edición. Madrid: Ecologistas en acción, 2015. Disponible en: https://spip.ecologistasenaccion.org/IMG/pdf/cuaderno_ruido_2013.pdf [ Accedido el 16 marzo 2020]

[4] Organismo de Evaluación y Fiscalización Ambiental (OEFA) "La contaminación sonora en Lima y Callao", 2015. Disponible en: https://www.oefa.gob.pe/?wpfb_dl=19087 [Accedido: 12-ene-2020]

[5] C.E. Aramburu y W. Mendoza. El futuro de la población peruana, problemas y oportunidades. Revista debates en sociología. №41, pp.5-24, 2015. Disponible en: file://C:/Users/User/ Downloads/14623-Texto\%20del\%20art\%C3\%ADculo-58096-3-10-20151230.pdf [Accedido el 18 de marzo 2020].

[6] B. Garcia y F.J. Garrido, La contaminación ambiental acústica en nuevas ciudades. Barcelona: Fundación La Caixa.2003. Disponible en: https://www.camarazaragoza.com/medioambiente/ docs/publicaciones/publicacion56.pdf [ Accedido el 16 de marzo 2020]

[7] C. Andaluz, Manual de Derecho Ambiental. Lima: Iustitia, 2011.

[8] H. Carhuatocto, Guia de Derecho Ambiental. Lima: Juristas Editores, 2009.

[9] I. Amable, I. Méndez, J. Martínez, L. Delgado, F. Acebo, M. De Armas, J, Rivero, Contaminación ambiental por ruido. Rev. Méd. Electrón [Internet]. 20,17 May-Jun.;39(3). Disponible en: http://www.revmedicaelectronica.sld.cu/index.php/rme/article/view/2305/3446. [Accedido: 12 ene 2020].

[10] R. Hernández y P. Mendoza, Metodología de la investigación. Las rutas cuantitativas, cualitativas y mixtas. 1ra Ed. D.F. México: Mc Graw Hill. 2018.

[11] J. Sánchez. Adela Cortina: El reto de la ética cordial. Revista Brocar. N³9 (2015) pp.397422. Disponible en: file://C:/Users/User/Downloads/Dialnet-AdelaCortina-5257685.pdf. [ Accedido el 16 marzo 2020]. 
